\title{
A intervenção do/a assistente social com pessoas idosas que residem em estruturas residenciais: Um estudo qualitativo a propósito das lógicas de projeto de vida
}

\author{
The intervention of social workers with elderly people living in residential \\ facilities: A qualitative study about the logic of life project
}

Ricardo Crispim ${ }^{1}$

\begin{abstract}
Resumo
Esta investigação tem por objetivo analisar a dinâmica do Serviço Social no campo gerontoinstitucional, à luz de uma reflexão sobre as várias expressões do EA e participação, em benefício de projetos de vida para e $n a$ velhice. A amostra envolveu cinco assistentes sociais que laboram em Estruturas Residenciais para Pessoas Idosas (ERPI) de cinco ERPI distintas. Os dados foram recolhidos por questionário sociodemográfico e entrevistas em profundidade (semiestruturada) prosseguindo uma abordagem essencialmente qualitativa (análise de conteúdo). Verificou-se nos principais resultados que desenhar projetos de vida para e na velhice em ambientes residenciais revelou de forma consistente estar apoiado, por um lado em padrões e diretrizes institucionalizadas e por outro lado, embora surjam a um ritmo tímido, em abordagens holísticas, abrangentes e multidimensionais. Estes resultados são promissores na forma como analítica e empiricamente se idealizam e concretizam projetos de vida em ERPI baseados nas novas expressões da(s) velhice(s), privilegiando lógicas interativas, integrativas e multidimensionais.
\end{abstract}

Palavras-chave: envelhecimento ativo, participação, estruturas residenciais para pessoas idosas, projeto(s) de vida.

\begin{abstract}
This research aims to analyze the dynamics of Social Work in the gerontoinstitutional field, in the light of a reflection on the various expressions of EA and participation, in benefit of life projects for and in old age. The sample involved five social workers working in Residential Structures for the Elderly (ERPI) from five different ERPIs. Data were collected through a sociodemographic questionnaire and in-depth interviews (semi-structured) following an essentially qualitative approach (content analysis). The main results showed that designing life projects for and in old age in residential settings consistently proved to be supported, on the one hand, by institutionalized standards and guidelines and, on the other hand, although emerging at a shy pace, by holistic, comprehensive and multidimensional approaches. These results are promising in terms of how analytically and empirically life projects based on the new expressions of old age(s) are conceived and implemented in residential care facilities, focusing on interactive, integrative and multidimensional logics.
\end{abstract}

Keywords: active aging, participation, residential structures for the elderly, life project(s).

\section{Introdução}

Atualmente os construtos Envelhecimento Ativo (EA) e participação assentam numa vasta, complexa e controversa gramática levando a uma ampla diversidade de

\footnotetext{
${ }^{1}$ Doutorando no Programa Interuniversitário de Doutoramento em Serviço Social da FPCE-UC | E-mail: rmscrispim@hotmail.com
} 
práticas, não se traduzindo, bastas vezes, em efetivas boas-práticas, equivalente evolução do conhecimento, concetualização e real implementação.

Neste seguimento, o exercício proposto neste trabalho visa revisitar criticamente os conceitos centrais na atuação profissional dos/as assistentes sociais em Estrutura Residencial para Pessoas Idosas (ERPI) - EA e participação -, ajudando a localizar analítica e empiricamente o conceito de projeto de vida para e na velhice, como também a ultrapassar a imprecisão e risco de retórica vazia que os ameaçam.

As investigações gerontológicas realizadas nos últimos anos, embora extensas e atuais, têm sido parcas em estudos relacionados com os projetos de vida na fase mais tardia da vida. Neste sentido, carece de se refletir, sendo o mote deste trabalho, a forma presumivelmente estandardizada de idealizar, desenhar, concretizar e avaliar projetos de vida em contextos residenciais, na medida em que o cuidado às pessoas idosas se tornou uma problemática visível pelas fragilidades que lhe estão subjacentes.

\section{Envelhecimento Ativo: Um construto em mudança}

A configuração do Envelhecimento Ativo (EA) e o seu enquadramento nas políticas e dinâmicas de intervenção, ocorrem num quadro de profunda complexidade estrutural, inscrevendo-o como um problema social de espetro bastante complexo e multidimensional (e.g., Luz, 2017; Marier \& Van Pevenage, 2017; Van Dyk, 2014). Este facto convida a uma revisitação aprofundada das expressões contemporâneas do construto EA.

A forma disruptiva como tem vindo a ser tratado deve-se, sobremaneira, à reconfiguração das suas bases outrora assentes em lógicas claramente biomédicas, embora agora tendencialmente mais variadas. O seu espetro analítico e empírico convoca e correlaciona as lentes socioeconómicas, psicológicas e ambientais, fundando-se na procura de elementos capazes de permitir a identificação do potencial do envelhecimento e no reconhecimento dos meios quer para a sua promoção positiva, quer para uma velhice mais próspera (Miguel \& Amaro da Luz, 2014).

Segundo Helena Amaro da Luz (2017), o objetivo principal do EA é o de alargar as vias de abordagem do envelhecimento e da velhice a fim de explorar o potencial das pessoas idosas. Neste sentido, a noção de EA pretende apresentar uma abordagem mais holística e orientada para o curso de vida (Foster \& Walker, 2015), intensificando a construção de uma perspetiva integrada do envelhecimento, ou seja, é concetualizado como "um processo de otimização das oportunidades de saúde, participação e segurança, 
com o fim de melhorar a qualidade de vida à medida que as pessoas envelhecem” (WHO, 2002, p. 12).

Apesar de o EA assentar numa imagem positiva, potenciadora da qualidade de vida dos indivíduos, este construto não está isento de discussão e análise crítica. Com efeito, partimos das análises de José de São José e Ana Rita Teixeira (2014), Liam Foster e Alan Walker (2015) e de Helena Reis Amaro da Luz (2017) para elencar algumas das principais críticas feitas ao EA.

Em primeiro lugar é destacada a nebulosa concetual dotando este como um conceito polissémico (Luz, 2017) decorrente do facto de tratar de uma noção criada "a partir de gabinetes" (José \& Teixeira, 2014, p. 47), sem que existam espaços de auscultação aos profissionais e, por exemplo, às pessoas idosas. Este facto confere certa dissonância na compreensão analítica e empírica (pela maioria dos interlocutores, nomeadamente pessoas idosas e profissionais) na forma como a comunidade académica pensa o conceito, tal como os agentes sociais o operacionalizam na esfera interventiva (Luz, 2017; José \& Teixeira, 2014).

Num segundo momento, evidenciamos a tendência neoliberal do conceito. Ou seja, embora a noção de EA se preocupe em facilitar os direitos e manter as pessoas o mais tempo possível saudáveis e a trabalhar (em termos remuneratórios), com o pretexto, algo ludibriante, de se manterem ativas e felizes na esfera privada e coletiva, estamos em crer que a lógica economicista deixe desvendar que um dos principais propósitos é diminuir os custos com as prestações sociais e assistência à saúde ${ }^{2}$ (Foster \& Walken, 2015; Luz, 2017; José \& Teixeira, 2014).

Um terceiro aspeto deste conceito centra-se no unirecionalismo que lhe serve de base. Isto é, para além de ter uma fraca correspondência com a realidade, faz com que muitas das pessoas idosas permaneçam na categoria de "passivas", experimentando sentimentos de falhanço individual e, inclusive, sentimentos de culpa por não contribuírem para a sociedade (José \& Teixeira, 2014). Com correspondência a este facto, em Portugal, segundo dados recolhidos no PORDATA (2020), a percentagem de população ativa por grupo etário situa-se da seguinte forma: o grupo etário 25-54 anos representa 76,2\% rivalizando com os parcos $22,4 \%$ das pessoas com 65 ou mais anos.

Como quarto aspeto, que nos parece caminhar em direção semelhante ao ponto anterior, temos o facto de ainda ser parca a bibliografia especifica acerca daquilo que tem

\footnotetext{
${ }^{2}$ Serve de exemplo o sucedido em Portugal aquando da governação do XVII Governo Constitucional.
} 
de ver com "envelhecer bem". Embora a produção científica referente aos processos de envelhecimento no âmbito do EA seja extensa e atual, não se encontram ainda analítica e empiricamente fundamentados referenciais que nos permitam alimentar substancialmente as intervenções a fim de estas se tornarem efetivamente inclusivas e não excludentes, desde logo porque nos parece claro que no conceito de EA não há lugar a pessoas idosas cognitiva e fisicamente vulneráveis (e.g., em termos de capacidade funcional). Ou seja, estamos perante um construto "padronizador" e "polarizador", desde logo porque se subentende a existência por um lado de pessoas idosas que "envelhecem bem" como seres humanos autónomos e competentes e, por outro lado, aqueles que não conseguem atingir esse padrão, por exemplo pessoas idosas com demência (Luz, 2017). A este nível, carece de se atender o facto de narrativas baseadas nos déficits, nas perdas e na dependência das pessoas idosas reforça indiscutivelmente um dos "ismos" mais aceites nas sociedades contemporâneas: o idadismo, que surge como um dos principais entraves à concretização do EA, apoiado, em parte, numa cultura de "anti-envelhecimento" e "atividade".

Por último, o quinto aspeto que se apresenta como fragilidade ao conceito de EA, faz referência à individualização do EA. Por exemplo, na definição de EA da OCDE (in José \& Teixeira, 2014, p. 48), é totalmente olvidado o ecodeterministo sob o qual se processa o envelhecimento, negligenciando os contextos macrossociais (públicos respetivos) e macrossociais (e.g., composição do agregado familiar, género, classe social, rede de serviços e equipamentos sociais, recursos financeiros).

Embora estejamos a tratar da operacionalização de construto que goza de influência do ambiente, autores existem que reforçam a narrativa assente na determinante pessoal (e.g., Chapin \& Cox, 2002; Mondaca et al., 2018; Petriwskyj et al., 2018; Schenell et al., 2020). Tal significa, que este não é somente um construto que tem de ver com o engajamento das pessoas idosas em atividades de carácter físico, social e político, mas também com a liberdade, possibilidade, capacidade e ferramentas que lhes são dadas para escolherem e decidirem ativamente como se querem envolver nas dinâmicas relacionadas com o envelhecimento. A possibilidade de escolher já constitui per si um pressuposto basilar do EA. Por exemplo, a ideia de que às pessoas idosas em situação de maior fragilidade e dependência não deve ser retirada a possibilidade de escolher e participar é explanada Barbra Teater e Jill Chonody (2017) ao referirem, que, “a única maneira pela 
qual os indivíduos podem falhar $^{3}$ no Envelhecimento Ativo é se o local onde residem os impede de manter a autonomia, escolha e participação" (Teater \& Chonody, 2017, p. 26).

\section{Participação das pessoas idosas: $O$ caso das ERPI}

À semelhança do EA, também a noção de participação goza de controvérsia, levantando dificuldades de definição e consenso. Atualmente ainda não foi estabelecido qualquer acordo sobre o que significa participação, o que "pode assumir significados muito diversos e remeter para variadas ações por diferentes atores" (Cornwall, 2008 in Almeida, 2016, p. 404). Com esta visão, importa esclarecer o que para nós significa participação. Assim, a leitura mais aproximada de participação para nós é um lugar de ação política alargada, interativa e dinâmica (i.e., negociada), comprometida entre vários interlocutores (e.g., de forma muito particular dos destinatários da ação) e ambientes, assente num processo pedagógico e democrático de permanente aprendizagem. Este tem em vista a (re)construção de oportunidades de desenvolvimento, de cidadania e de melhoria da tomada de decisão pessoal e social, por forma a serem atingidos níveis satisfatórios de autodeterminação, autocapacitação, empoderamento e protagonismo (Almeida, 2017; Dehi \& Mohammadi, 2020; Vieira, 2017). Por tal razão, a ação participativa não pressupõe que os interlocutores apenas "estejam presentes em", mas antes influenciem ativamente decisões e "ações" 4 com base nas suas opiniões (Crispim, 2020, p. 86).

Tendo por base outros estudos nossos, "hoje, é amplamente reconhecido que a participação das pessoas idosas na tomada de decisões sociais e políticas é, não só, desejável, mas essencial em qualquer sistema democrático" (Crispim, 2020, p. 85), embora se saiba da inexistência de qualquer acordo entre as dimensões participação e pessoas idosas, nomeadamente em temas que as afetem diretamente (Almeida, 2016; Casado, Sousa \& Touza, 2020).

Neste sentido, a noção de participação, associada ao EA, envolvendo a população mais envelhecida, não constitui um exercício teórico e prático frequente (e.g., Almeida,

\footnotetext{
${ }^{3}$ Expressão entre aspas no texto original.

${ }^{4} \mathrm{O}$ termo ações é por nós usado, pois é um conceito mais amplo do que atividades e inclui ações como pensamento e reflexão (Gustavsson, Liedberg \& Ranada, 2015 in Crispim, 2020).
} 
2016; Rede Europeia Anti-Pobreza/Portugal [REAP], 2017), sendo esta uma evidente fragilidade que apontamos no que à participação diz respeito. Esta infrequência, em parte, decorre do facto de ainda permanecer relativamente às pessoas idosas a estereotipia de que estas, e de forma muito particular as pessoas idosas em situação de vulnerabilidade (e.g., em termos de funcionalidade cognitiva e física), são pessoas desinteressadas por uma ampla gama de questões, designadamente, de natureza política, social e cultural e que se encontram estagnados e ultrapassados pela contemporaneidade do tempo (Pinto, 2013).

Mariana Almeida (2016) apresenta outra fragilidade, levantando a questão de muitos estudos (quantitativos e qualitativos) analisarem as abordagens e grupos padrão, embora sejam pouco esclarecedoras acerca das circunstâncias e "estruturas de oportunidade" onde a participação se concretiza e a razão pela qual os grupos obedecem a um modelo estanque (e.g., pessoas idosas funcional e cognitivamente autónomas). Invocando alguns estudos no seu trabalho, Mariana Almeida (2016) acrescenta que não se conhecem ainda investigações portuguesas de carácter mais abrangente que incidam em iniciativas e ações de participação especifica para pessoas idosas, concretizadas, por exemplo, ao nível local e com demais públicos (e.g., pessoas idosas com psicopatologias e/ou com mobilidade reduzida). Mais se acrescenta fundamental que as vozes de todos os interlocutores, independentemente das características (e.g., funcionais, cognitivas, culturais) têm de ter peso igual naquilo que é o processo participativo (Petriwskyj, Gibson \& Webby, 2018).

Dos vários significados, sentidos e conotações atribuídos à noção de participação, eclode outra fragilidade ocorrida em múltiplas arenas no campo da Gerontologia, que trata precisamente do presumível paternalismo invalidante e rigidez da atuação, ainda que o uso da componente da participação ativa e cívica dos públicos seja mencionada. Em virtude dos atuais contextos sociais apresentados aos profissionais das ciências sociais e humanas e da saúde, tem-se vindo a assistir à padronização de práticas plasmadas naquilo que é o construto da participação em contextos gerontológicos (e.g., ERPI). Hoje, estamos perante dinâmicas do social mais criativas e inovadoras, embora o uso indiscriminado do conceito participação represente, segundo Helena Neves Almeida (2017, p. 47), uma "quase moda a que todos os profissionais aderem em contextos diversos", apesar de não se traduzir necessariamente "em equivalente evolução do conhecimento, concetualização e efetiva implementação" (Almeida, 2016, p. 404). Neste contexto Isabel Guerra (2002, p. 102) refere como uma das causas desta discricionariedade o facto de "sem 
conhecimento muito próximo das necessidades dos destinatários e dos restantes atores que detêm recursos para lidar com os problemas, qualquer projeto não passará de um documento escrito". Isto leva-nos à próxima fragilidade colocada à participação das pessoas idosas em ERPI.

Atualmente sabe-se que o espaço cuidativo às pessoas idosas em estrutura residencial, tem sido caracterizado por uma elevada dependência de processos formais (i.e., pelo controlo, gestão de risco e foco na patologia), reduzindo a margem de independência das pessoas idosas, levando por um lado ao comprometimento do exercício da liberdade, da autonomia, da capacidade de tomada de decisão e da participação plena, e por outro lado à diminuição do autoconceito e autoestima, da privacidade, do sentido de pertença e do bem-estar (HerazoBeltrán et al., 2017; Medeiros et al., 2020; Nogueira et al., 2016; Petriwskyj, Gibson \& Webby, 2018). Tal significa que em instituição a pessoa idosa vive problemas decorrentes do "confinamento às regras institucionais de enquadramento dos serviços que recebe, normas em que não participou" (Almeida, 2012, p. 153). Isto é, as atuais dinâmicas participativas em teoria apresentam uma configuração baseadas nos pressupostos teóricos contemporâneos, embora, as práticas interventivas ditem tratar-se de uma participação paternalista, pseudoparticipação ou participação diretivocolaborativa (e.g., Casado, Sousa \& Touza, 2020; Crispim, 2020; Crispim \& Luz, 2020; Petriwskyj, Gibson \& Webby, 2018). A título de exemplo, socorremo-nos do trabalho de Andrea Petriwskyj, Alexandra Gibson e Glenys Webby (2018). No estudo que tinha como objetivo explorar a prática do envolvimento das pessoas numa estrutura residencial de grande dimensão, a fim de compreender as dinâmicas de ativação que estavam a ser implementadas, como estavam a ser desenvolvidas e em que medida as pessoas idosas participam na prestação de serviços a nível individual, comunitário/local e organizacional, apurou-se que as estratégias participativas baseavam-se fundamentalmente em domínios consultivos (e.g., reuniões de residentes e/ou disposições de emissão de reclamações), operando mais frequentemente como consulta ao invés de pleno exercício de cidadania.

\section{Projetos de vida: A urgência de uma gramática renovada em ERPI}

Aplicado à velhice, os estudos dos projetos de vida têm merecido pouco destaque por parte da comunidade académica. Globalmente, as parcas pesquisas existentes acerca dos projetos de vida na velhice e/ou aquelas que bebem das lógicas de "projetos" têm sido caracterizadas pela utilização de índices de saúde como indicadores de qualidade de vida 
- capacidade funcional, bem-estar psicológico, apoio social, saúde, dependência, coping, adaptação -, sem referência ao modo como as pessoas idosas em geral ou grupos específicos em particular definem os seus próprios projetos de vida ou ao valor que atribuem a cada um dos componentes que enquadram a fase da velhice (e.g., Santana, Bernardes \& Molina, 2016; Petriwskyj, Gibson \& Webby, 2017). Ademais, a abordagem científica e profissional quando aborda as lógicas de projetos de vida tem, não só, tendido a homogeneizar as pessoas idosas, como também a privilegiar grupos de pessoas saudáveis excluindo os indivíduos que padecem, nomeadamente, de algum tipo de psicopatologias e/ou dificuldade motora ou outra.

A propósito do facto de a projeção da fase mais tardia da vida não gozar de particular interesse por parte da comunidade académica e das práticas, esta bebe de interpostas noções ${ }^{5}$ por forma a ganhar consistência na investigação e na intervenção. Socorremo-nos agora de alguns trabalhos onde se aborda a noção de projeto de vida ou equivalentes (Quadro 1).

Quadro 1. Síntese das abordagens de noção de projeto de vida ou equivalentes

\begin{tabular}{cl}
\hline & "o desejo de transformar o cotidiano, considerando elementos \\
& importantes do passado e do presente, almejando algo melhor para o \\
futuro. Eles se desenvolvem em uma organização multidimensional e \\
Projeto de vida \\
são atravessados por aspetos objetivos e subjetivos advindos da \\
experiência e trajetória de vida pessoal” (Marcelino, Catão \& Lima, \\
2009 in Santana, Bernardes \& Molina, 2016, p. 172). \\
\hline Uma metodologia de estudo que permite compreender as ações e o \\
Projetos pessoais \\
comportamento humano em múltiplos espaços e contextos, sendo \\
definido como um conjunto de ações intencionais e relacionadas entre \\
si com vista à realização de objetivos pessoais (Little, 1983).
\end{tabular}

\footnotetext{
${ }^{5}$ Serve de exemplo: desafios do processo de acolhimento, dos processos identitários, dos direitos das pessoas idosas, processos democráticos, intervenções para melhorar a qualidade de vida, entre outros construtos.
} 
Assim, em primeiro lugar, projetar a fase mais tardia da vida implica um longo processo extensivo ao ciclo da vida humana, tal como envelhecer ativamente, pelo que, "deve ser preparado desce cedo" (Forum para a Governação Integrada [GovInt], 2014). Este processo requer uma abordagem holística, abrangente e multidimensional com o intuito de materializar no futuro objetivos presentes, podendo funcionar como fonte de motivação. Significa isto que nunca é tarde para desenhar projetos de vida que permitam aumentar o desenvolvimento humano e diminuir a passividade, inércia e descrença fase ao futuro. Contrariamente a este último aspeto, acrescenta-se que o propósito de vida (Santos, et al., 2019) e o otimismo no futuro (Durbin et al., 2019) tendem a ser menor, principalmente na transição da meia-idade para a fase da velhice, alertando para uma realidade ambígua: viver mais anos não se traduz necessariamente numa fase significativa da vida (e.g., Apouey, 2018; Hees et al., 2015; Santana, Bernardes \& Molina, 2016; Santos et al., 2019).

No respeitante a este assunto, estudos indicam que a transição para a velhice traz menos consistência aos projetos de vida (Santana, Bernardes \&Molina, 2016; Apouey, 2018) ${ }^{6}$. Este fenómeno pode ter explicação, em parte, (a) na prevalência das noções tradicionais de velhice junto da esfera social e familiar, pautadas pelo predomínio de dimensões que enfatizam o declínio, a incapacidade, a perda e a dependência; (b) nos rendimentos baixos que impossibilitam, por exemplo, contratualizar seguros de vida e de saúde; (c) na perceção débil presente e futura do estado de saúde, bem como elevada probabilidade futura de se tornar dependente de outrem; (d) expetativa de longevidade curta; (e) egoísmo; (f) na capacidade cognitiva e motora biologicamente mais enfraquecida; levando à (g) desmotivação fase ao futuro e à menor possibilidade em atingir a autorrealização fruto.

Em segundo lugar, a perspetiva de projeto de vida na velhice beneficia analítica e empiricamente de "alterações normativas ou patológicas do envelhecimento" (Santos, et al, 2019, p. 370), que, a par da componente biomédica, deve considerar também a componente psicológica e social. Neste sentido, segundo Julia Linari (2014 in Santana,

\footnotetext{
${ }^{6}$ Os estudos referidos que tinham como objetivo identificar os projetos de vida das pessoas idosas e os moldes em que eram desenhados. O primeiro trabalho da autoria de Carla Santana, Marina Bernardes e Amanda Molina (2016), tinha como objetivo identificar os projetos de vida de pessoas idosas a curto, médio e longo prazo, onde, das 150 pessoas idosas auscultadas, 41 referiram não projetar o futuro. Neste trabalho, das 150 pessoas auscultadas, 41 não preparavam a fase mais tardia da vida. No segundo trabalho, de Bénédicte Apouey (2018), avaliou-se o papel das preferências e expectativas na preparação para a velhice, empregando dados exclusivos sobre franceses com mais de 50 anos. Neste segundo estudo, metade dos indivíduos que compunham a amostra (a amostra era composta por 1.244 pessoas com idades compreendidas entre os 40 e os 84 anos de idade) não se preparava para a velhice.
} 
Bernardes \& Molina, 2016, p. 181) "planear o futuro em qualquer fase da vida está diretamente relacionado ao resgate da potencialidade humana na busca pela realização política, cultural, psicológica e social". Na medida em que a "construção de projetos de vida é fundamental pois pode prevenir a longo prazo o aparecimento de sentimentos de inutilidade e de baixa autoestima” (Forum para a Governação Integrada [GovInt], 2014, p. 134). A este propósito, no estudo levado a cabo por Aliya Alimujiang e sua equipa (2019) com vista a avaliar a existência de relações entre propósito de vida e mortalidade por todas as causas ou causas específicas entre adultos mais velhos nos Estados Unidos, conclui-se que um propósito de vida mais sólido decorre, entre outras consequências, de menor mortalidade, ou seja, uma vida com propósito parece trazer maiores benefícios à saúde.

Finalmente, esta reflexão leva-nos a um terceiro aspeto que está conexo à lógica ecodeterminante dos projetos de vida operacionalizados nas organizações do cuidado. Isto é, a prática não é concebida como algo circunstancial, subjetiva e dissociada do(s) contexto(s) (i.e., local e global), mas antes "como produto da articulação entre objetividade e subjetividade e entre ação e estrutura", na medida em que a "ação e estrutura não se opõem, mas interligam-se e influenciam-se mutuamente de modo mais ou menos (im)previsível" (Albuquerque \& Arcoverde, 2017, p. 13-14). Cristina Albuquerque e Ana Cristina Arcoverde, a este nível acrescentam que desta forma "são ultrapassadas as dicotomias micro/macro, objetivo/subjetivo, em prol de uma abordagem holística das ações situadas" (Albuquerque \& Arcoverde, 2017, p. 13-14). Neste sentido, ganha consistência operacional a dinâmica interativa, "circular" de "influência mútua" (Albuquerque \& Arcoverde, 2017, p. 16) que pode ocorrer efetivamente entre estruturas sociais - neste caso ERPI - e os indivíduos (i.e., pessoas idosas). Em suma, consequência de lógicas ecodeterminantes e interdependentes, as realidades das estruturas sociais podem ser alteradas a todo o momento por via da capacidade reflexiva de que o Homem é detentor.

Neste trabalho, de natureza exploratória, pretendemos sobretudo analisar a dinâmica do Serviço Social no campo gerontoinstitucional, à luz de uma reflexão urgente sobre as várias expressões do EA e da participação, em benefício de projetos de vida para e $n a$ velhice. 


\section{Metodologia}

Tendo em consideração o objetivo atrás mencionado, levou-se a cabo um estudo conduzido a partir de uma metodologia qualitativa com assistentes sociais que laboram em ERPI. Foi também usada a metodologia quantitativa simples.

\section{Considerações éticas}

Foi lido e assinado em duplicado por todos os participantes do presente estudo um consentimento informado, esclarecido e livre para participação em estudo de investigação com a finalidade de assegurar a confidencialidade e anonimato dos dados que foram recolhidos para fins de investigação.

\section{Amostra}

Os participantes que constituem a amostra foram recrutados em cinco ERPI. A amostra por conveniência da presente investigação é composta por cinco assistentes sociais (a totalidade do sexo feminino). A média de idades oscilava entre os 34 e os 57 anos, sendo a média de 44,4 anos, a desempenhar funções no quadro técnico ou da direção técnica organizacional das estruturas, em média há 14,7 anos. No plano profissional, ainda que todas possuíssem licenciatura em Serviço Social, também 20\% detinham outras formações, nomeadamente uma inquirida possuía formação na área da mediação familiar, gestão (e.g. recursos humanos), estimulação cognitiva, entre outras; e outra inquirida tinha a Licenciatura em Animação Sociocultural e a Pós-Graduação em Intervenção Social. Em termos de experiência de trabalho junto da população idosa mais de metade das assistentes sociais auscultadas (60\% - três indivíduos) tinha experiência em ERPI, e a maioria considerou ter três ou mais anos de experiência na ERPI na qual trabalhava à data da entrevista.

\section{Procedimento}

A recolha de dados foi realizada nos concelhos de Alcácer do Sal, Campo Maior, Montemor-o-Velho, Leiria e Lisboa (i.e., Portugal). As ERPI foram selecionadas através da internet (i.e., através do motor de busca Google com a evocação de expressões várias como por exemplo «Lar de idosos + Humanização»), bem como do conhecimento prévio do autor do estudo. Previamente à recolha de dados, foi solicitado aos dirigentes das ERPI autorização para a realização do estudo.

Os critérios de inclusão definidos centraram-se em: a) ter habilitações literárias em Serviço Social (i.e., licenciatura) e b) exercer atividade profissional em ERPI há três ou mais anos. 


\section{Instrumentos}

No que aos instrumentos de recolha de dados diz respeito, este estudo beneficiou do questionário sociodemográfico (visando recolher informações relativas à idade, sexo, estado civil, habilitações literárias, profissão) e de entrevistas em profundidade (semiestruturada) contemplando perguntas abertas e fechadas. A entrevista aplicada às assistentes sociais estruturou-se em sete eixos de análise/temas ${ }^{7}$, embora para este trabalho apenas nos foquemos no eixo "Práticas e procedimentos do Serviço Social em ERPI mobilizadoras da participação das pessoas idosas no seu projeto de vida".

\section{Análise dos dados}

O tratamento e interpretação dos dados beneficiou da técnica de análise de conteúdo, seguindo a abordagem temática categorial. Nos termos de Bardin (2016), esta técnica permite fazer uma descrição objetiva, sistemática e quantitativa do conteúdo manifestado das comunicações, tendo por objetivo efetuar inferências, com base na explicitação das mensagens cujas características careceram de inventariação e sistematização interpretativa.

\section{Resultados}

A análise de conteúdo das entrevistas das cinco assistentes sociais (no Quadro 2 apresentadas como "E" (Entrevistada) permitiu categorizar em unidades de sentido decorrente do guião usado. O Quadro 2 apresenta um compêndio das categorias mais relevantes para o domínio deste trabalho.

Quadro 2. Categorias e Unidades de Sentido das assistentes sociais auscultadas

\begin{tabular}{ll}
\hline \multicolumn{1}{c}{ Categoria } & \multicolumn{1}{c}{ Unidade de Sentido } \\
\hline & \multicolumn{1}{c}{ Autonomia: "para nós cuidar não é fazer pelo seu pai, cuidar é ajudar } \\
& para que o seu pai cuide dele próprio" (E1); \\
\cline { 2 - 2 } Segurança como preditivo à autonomia: "Por isso nós temos de nos \\
Autonomia e & tegar à frente pela segurança e bem-estar deles. A autonomia é um \\
segurança & segurança (...) infelizmente. (...) os idosos entram para esta \\
& instituição, um bocadinho na procura da segurança" (E3); "A \\
& segurança. Porque temos muitas pessoas dependentes e sem nós elas \\
\hline
\end{tabular}

\footnotetext{
7 São eles: I) Dados de caracterização: elementos relativos ao assistente social; II) Dados relativos à organização de enquadramento da ERPI; III) Caracterização geral da população sénior para quem o/a profissional trabalha; IV) Vertentes da participação das pessoas idosas na dinâmica/estratégia institucional e nas atividades institucionais; V) Práticas e procedimentos do Serviço Social potenciadoras da participação na estratégia institucional (plano macro); VI) Práticas e procedimentos do Serviço Social em ERPI mobilizadoras da participação das pessoas idosas no seu projeto de vida (plano micro); VII) Implicações (oportunidades e constrangimentos) associadas à envolvência colaborativa.
} 
Princípios associados à intervenção profissional junto dos idosos

não conseguiam sobreviver. Promover a autonomia tudo bem, mas chega a um ponto em que a segurança é fundamental" (E4); "Eu tenho aqui até, neste momento, uma utente que já deu várias quedas na rua e eu por uma questão de segurança, lá está, acabo por pedir à utente para não sair" (E5).

Princípio da liberdade, autodeterminação e participação: "Eu acho que o princípio basilar (...) é a questão da dignidade (...) às vezes os profissionais têm por hábito colocar-se um bocadinho à frente dos residentes. Mais do que "- Aquilo que eu gostaria de fazer", é “- O que é que eles gostariam de fazer?" Ou seja, este respeito pela individualidade, pela decisão, pelo processo de decisão, da autonomia" (E1), "[Princípios que estão na base do desenho do projeto de vida da pessoa idosa em ERPI] Para já a vontade de próprio e a participação dos familiares. [O que é que prevalece mais: a vontade do próprio ou a vontade da família?] A vontade de próprio (E2), "E não as limitar. Fazer pelo menos com que todos os dias elas tenham dignidade, elas concretizem alguns desejos" (E5).

Princípio da padronização assente na promoção do direito de bemestar: "Nós, na parte da integração, os idosos que nos permitem isso, nós ouvimos as suas expectativas e eles são informados do plano individual de cuidados que nós somos obrigados a fazer e é uma das orientações da Segurança Social, é o plano individual de cuidados e trabalhar tudo. Neste caso, quando projetamos o plano individual de cuidados, falamos da própria prestação dos serviços, alimentação, higiene, mas depois temos toda a parte do bem-estar social, o apoio psicossocial, o trabalhar com as famílias, o trabalhar com o idoso em situações de crise" (E3); "Nós temos aquelas fichinhas todas, os PDI [Plano de Desenvolvimento Individual] e isso" (E4).

Consideração da experiência/percurso de vida das pessoas idosas: "Para já é necessário conhecer o contexto do idoso, a sua profissão,

Mecanismos para estimular a participação/ativação das pessoas idosas no seu projeto de vida os seus gostos e os seus interesses" (E2); "Motivá-los, ouvi-los, sempre, e perguntar, o que é que esperam, quais são as expectativas, o que é que eles esperam quando entram para um Lar” (E3); “(...) a primeira intervenção é o acolhimento (...) Há sempre uma canalização para a parte da enfermagem porque aí tem de ser sempre (...) Para saber os antecedentes todo o historial clínico depois a partir daí é que se começa a trabalhar na outra área de comunicação, (...) e 
é através desse conhecimento que temos de dar a conhecer e fazemos sempre (...): os planos" (E4).

Trabalho conjunto com a pessoa idosa: “(...) as atividades são propostas, são discutidas, são executadas de acordo com a vontade deles" (E2); "Existe o envolvimento deles [pessoas idosas] sim" (E4).

Desencadeamento de projetos/dinâmicas de intervenção que atendam às distintas situações-problema que se apresentam: "Não vamos recusar os cuidados que são prestados ou os gostos dos utentes, temos sim é de ir ajustando os gostos e os hábitos dos utentes também à nossa dinâmica” (E2); “(...) porque elas [cuidadoras] têm de respeitar aquela pessoa, porque é uma pessoa, não somos uma fábrica" (E3); "Nós temos de adaptar a cada situação. (...) temos de os cativar de alguma forma para haver uma troca" (E4).

Projeto de vida da pessoa idosa em ERPI permanentemente metamorfoseado por vontades e motivos vários: "Eu acho muito importante toda aquela informação que nós conseguimos antes da integração (...) Desde conflitos familiares, desde pessoas em que há uma relação mais próxima, aquilo que eles gostavam de fazer, aquilo que eles não gostavam de fazer" (E1); "O projeto de vida (...) tem de ser construído por todos os técnicos e não só pelo assistente social.

Intervenção

profissional

associada à conceção

do projeto de vida da pessoa idosa em instituição
Tem de ser um trabalho conjunto, e é um projeto de vida que se vai construindo não é fixo, não é desenhado numa segunda-feira e está pronto numa sexta e é para continuar assim até ao último dia de estadia do nosso idoso. Portanto, é um trabalho dinâmico, que muda de acordo com as vontades deles, com as nossas vontades, com as nossas capacidades e funcionalidades, com as nossas dinâmicas e recursos" (E2); "É assim, eu acho que a assistente social não tem de fazer nada. É assim, acho que tem de ser o idoso a indicar-nos o caminho por onde ainda quer seguir" (E5).

$\underline{\text { Família enquanto interlocutor privilegiado no desenho do projeto de }}$ vida da pessoa idosa em ERPI: "Há muito trabalho que nós temos de fazer com as famílias, porque nós ao passar a ter aqui o familiar como residente, não decidimos a vida dele, e os laços familiares não devem ser perdidos" (E1).

Desafios e aspetos de Garantia dos direitos da participação e da dignidade da pessoa idosa melhoria que tendo por base as idiossincrasias: "Acho que o grande desafio é fazê- 


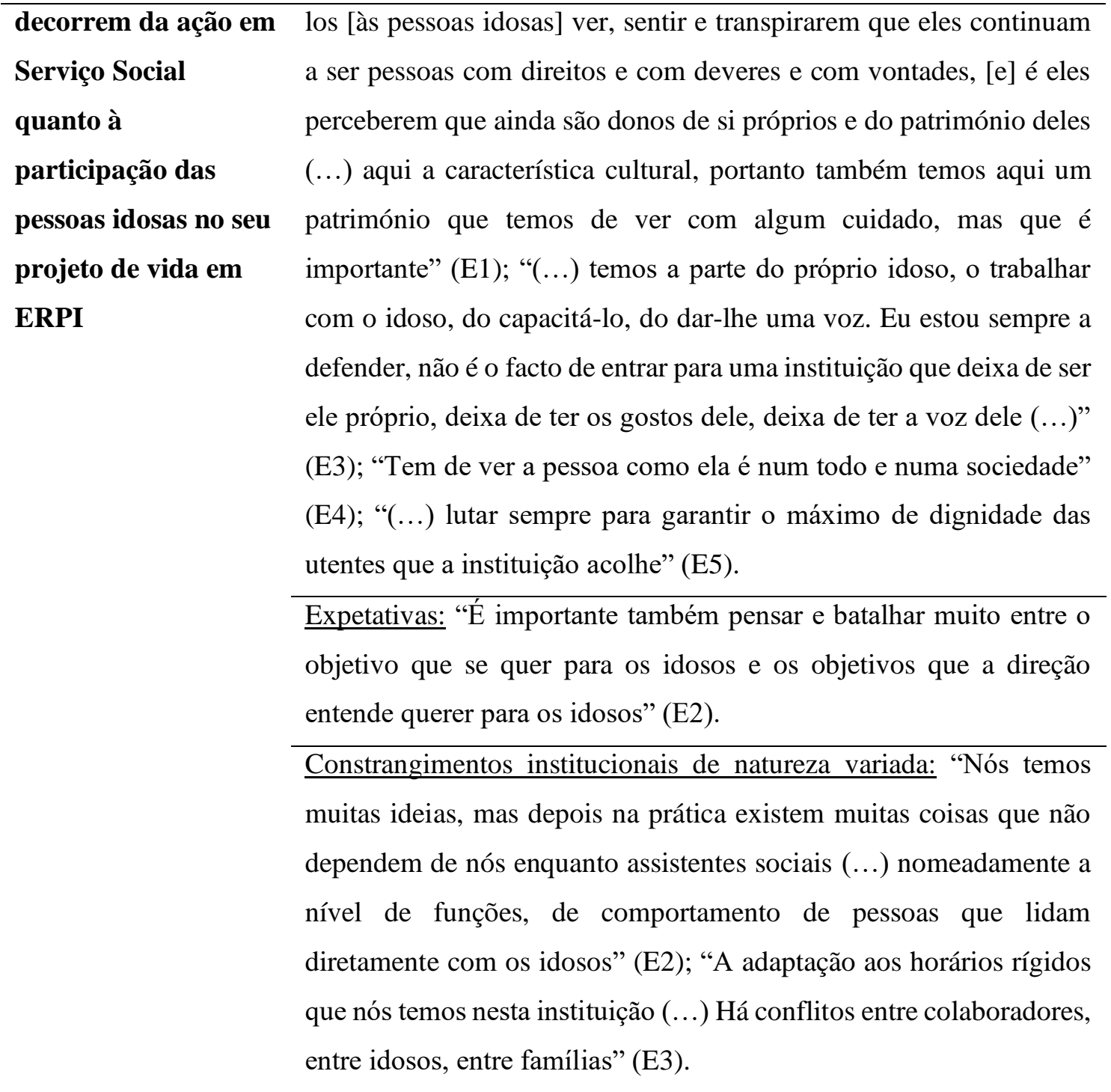

\section{Discussão}

Do ponto de vista daquilo que analisámos no quadro teórico, as disposições associadas ao EA expressam configurações intimamente relacionadas com a ativação da participação das pessoas idosas (de forma mais ou menos evidente), embora existam desajustes face às atuais expressões da velhice. Naquilo que à construção do projeto de vida da pessoa idosa em ERPI diz respeito, é central nas práticas das assistentes sociais auscultadas a existência de motivações de cidadania. Devido, em parte, aos fenómenos associados ao processo de participação e ativação das pessoas idosas em ERPI, as assistentes sociais (auscultadas) tendem, paulatinamente, a produzir discursos emancipadores referentes ao cuidado dos idosos, encontrando paralelo com os pressupostos teóricos associadas às novas leituras teóricas e empíricas do EA (Foster \& Walker, 2015; WHO, 2002). Estamos, deste modo, perante uma tempestade silenciosa 
que parece dar conta da existência de um esforço que está a ser feito a favor do efetivo exercício quotidiano de cidadania das pessoas idosas em contextos gerontoinstitucionais. Parece ser, no entanto, decorrente da literatura (e.g., Crispim, 2020; Teater \& Chonody, 2017), uma ainda pequena percentagem de ERPI que o faz.

Estes aspetos, permitem-nos afirmar que as especificidades detetadas na análise deste ponto remetem-nos para a noção de autonomia e segurança promovida pelas ERPI, na medida em que nos é sugerido pela literatura que nas arenas gerontoinstitucionais, pela natureza das pessoas idosas que as procuram (i.e., idosos funcional e cognitivamente mais dependentes) e pela forma como as ERPI estão atualmente estruturadas (Gabinete de Estratégia e Planeamento [GEP], 2018), os serviços são centralizados nos cuidados de saúde e segurança e menos na participação cívica e na autonomia dos seus beneficiários (e.g., Almeida, 2012).

Neste seguimento, os resultados evidenciados pelas assistentes sociais, ao longo da análise empírica, tendem a sugerir a existência de uma tendencialização para a segurança, encontrando paralelo com o estudo desenvolvido por Ramona Schenell e sua equipa (2020). No entanto, a segurança, à luz dos relatos das assistentes sociais, remete-nos como preditor à autonomia num sistema democrático, capaz de assegurar a concretização plena da participação. Ou seja, só com a garantia de segurança (não no sentido inibitório, mas sim o conjunto de ações e dos recursos utilizados para proteger a pessoa idosa) se pode caminhar rumo à estabilidade/apoio à existência de autonomia, o que conduz por seu lado à participação ativa em temas que afetam diretamente as pessoas idosas (Almeida, 2016; Casado, Sousa \& Touza, 2020).

A prevalência da segurança pode também induzir-nos ao facto de as assistentes sociais considerarem que algumas pessoas idosas, nomeadamente aqueles mais dependentes funcional e cognitivamente, desconsideram múltiplos riscos (e.g., risco de queda), imprimindo na cultura do cuidado às pessoas idosas em ERPI, procedimentos mais diretivos e rígidos (Schenell et al., 2020). Este fenómeno, como abordámos na primeira parte deste trabalho, pode levar a posturas mais "passivas", à inibição do exercício da liberdade, da autonomia, da capacidade de tomada de decisão e da participação plena, tal como à diminuição do autoconceito e autoestima, da privacidade, do sentido de pertença e do bem-estar (HerazoBeltrán et al., 2017; Medeiros et al., 2020; Nogueira et al., 2016; Petriwskyj, Gibson \& Webby, 2018; José \& Teixeira, 2014). Isto prova um certo unilateralismo que serve de base à intervenção destas profissionais, fortalecendo uma das fragilidades do construto EA que se baseia, em parte, na visão 
biomédica como é levada a cabo a intervenção junto de pessoas idosas (Miguel \& Amaro da Luz, 2014).

Carece de se atender que das assistentes sociais auscultadas, apenas uma (E1) imprime no seu discurso a lógica da autonomia. Deste contributo podemos destacar o facto da ERPI em questão estar a trabalhar no sentido da Certificação em Humanitude, pelo que nos pareceu natural que a referida assistente social evidenciasse a autonomia em detrimento da segurança.

Acerca dos princípios associados à intervenção profissional junto das pessoas idosas, ganha particular relevância junto das assistentes sociais, o lugar que ocupa o princípio da liberdade, autodeterminação e participação. Todavia, em lógicas opostas ocorra, ainda que com menos preponderância, a existência do princípio da padronização assente em diretrizes definidas, por exemplo, por entidades como o Instituto da Segurança Social, I.P. Nesta última, assistimos a uma ação centrada em instrumento de racionalização, numa atividade social claramente administrativa baseada em dinâmicas mais pseudoparticipativas ou participação diretivocolaborativa (e.g., Casado, Sousa \& Touza, 2020; Crispim, 2020; Crispim \& Luz, 2020; Petriwskyj, Gibson \& Webby, 2018).

Adicionalmente, constitui matéria de análise os mecanismos para estimular a participação/ativação das pessoas idosas no seu projeto de vida. Emergem daqui três pontos de reflexão: a) a consideração da experiência/percurso de vida das pessoas idosas, b) o trabalho conjunto entre os profissionais e a pessoa idosa; e c) o desencadeamento de projetos/dinâmicas de intervenção que atendam às distintas situações-problema que se apresentam. Um primeiro aspeto concentra-se no exercício de avaliação diagnóstica, ocorrendo em duas fases: uma baseada nas forças e recursos existentes e disponíveis, outra baseada nos problemas e deficits apoiada no conhecimento próximo da realidade (Guerra, 2002). Num segundo ponto, destacamos alguns relatos que dão conta da importância do trabalho conjunto com a pessoa idosa, induzindo uma clara alusão à ocorrência de ações desenhadas pelo coletivo, assente numa lógica "circular" de "influência mútua" (Albuquerque \& Arcoverde, 2017, p. 16) traduzindo-se como o corolário desejável referenciado pela literatura (e.g., Chapin \& Cox, 2002; Mondaca et al, 2018; Schenell et al, 2020; Petriwskyj, Gibson \& Webby, 2018). Com efeito, recai no terceiro ponto, tal como também fora apresentado nos trabalhos de Rosemary Chapin e Enid Cox (2002) e Ramona Schenell e sua equipa (2020), a existência de projetos/dinâmicas de intervenção que atendam às distintas situações-problema que se apresentam, colocando o enfoque numa ação baseada na adaptação dos cuidados 
prestados pelas ERPI à luz das escolhas das pessoas idosas, pretendendo dar conta das consequências positivas na vida das pessoas idosas, numa perspetiva em que estes são vistos como pessoas de direitos, que importam ser ouvidas e significadas, e não como pessoas desinteressadas em temas que as afetam (Pinto, 2013). É de suma, referir que, mais uma vez, não existe um tendencialização na forma de atuar quanto aos mecanismos para estimular a participação/ativação das pessoas idosas numa esfera micro, havendo, no entanto, uma tentativa evidente em focar a ação com a pessoa idosa como um todo individual, contínuo e não estático, sendo esta uma janela aberta à idealização, concretização e avaliação de projetos de vida em ERPI mais prósperos.

Para aquilo que queremos trabalhar neste ponto é da mais elementar justiça invocar a intervenção profissional associada à conceção do projeto de vida do idoso em instituição. Dos relatos da maioria das assistentes sociais, apurámos que estas imprimem no ADN da concretização do desenho do projeto de vida das pessoas idosas em ERPI, as escolhas, as opiniões e as preocupações (e demais dimensões) destas (Petriwskyj, Gibson \& Webby, 2018). Isto é, o projeto de vida em ERPI encontra-se em permanente transformação por vontades e motivos vários, fenómeno que intitulamos de perspetiva metamorfósica, interligada e influenciada do cuidado. Ou seja, da relação dialógica e "circular" (Albuquerque \& Arcoverde, 2017, p. 16) entre as aspirações das pessoas idosas e a necessária (re)configuração das ERPI, eclodem práticas diferenciadoras emanadas de uma interface permanente os beneficiários e a ERPI onde estes residem. Esta perspetiva leva-nos a outro ponto no plano do projeto de vida, que associa alguns dos interlocutores privilegiados nesta missão, designadamente a família. Tal como Helena Amaro da Luz (2014) enfatiza, a ação conjunta e a partilha coresponsabilizada entre uma pluralidade de agentes perfilados entre as pessoas idosas, a ERPI e as famílias tende a favorecer uma dinâmica real de ativação no envelhecimento e da velhice. Dinâmicas desta natureza contraiam as lógicas unidirecionalistas presentes, por exemplo, no conceito de EA da OCDE (in José \& Teixeira, 2014, p. 48).

Neste ponto enveredamos por uma nova senda de investigação, centrada na análise dos desafios e aspetos de melhoria. Deste ponto há a destacar: a) a garantia dos direitos da participação e da dignidade da pessoa idosa tendo por base as idiossincrasias; b) as expetativas; e c) os constrangimentos institucionais de natureza variada. $\mathrm{O}$ primeiro aspeto, inscreve-se essencialmente numa dimensão subjetivada da leitura que se faz da pessoa idosa. Isto é, a dimensão mais subjetiva das pessoas idosas é valorizada sobremaneira a ponto de em relação a cada beneficiário ser previsto um cuidado 
diferenciado (nas mais variadas disposições, e.g., sociocultural, cuidado direto), realçando-se a par, a importância que os direitos, os deveres e as vontades das pessoas idosas têm. Neste domínio ganha força a emergência do desenho dos projetos de vida das pessoas idosas em ERPI beneficiarem de uma abordagem holística, abrangente e multidimensional (Marcelino, Catão \& Lima, 2009 in Santana, Bernardes \& Molina, 2016).

O segundo aspeto faz-se balancear entre elementos de «expetativa» das pessoas idosas e a forma como se organiza a ERPI. Isto é, a componente diretiva do cuidado (nas mais variadas dimensões) representa, no quadro dos desafios das assistentes sociais, um ponto central "no fazer". Assim, promover a participação e a ativação das pessoas idosas a partir de uma cultura diretiva e unilateral, não trará efeitos libertadores nem de autonomização, mas antes opressão conforme nos prova a literatura (e.g., Schenell et al., 2020).

Por último, é destacada pela maioria das assistentes sociais constrangimentos vários, principalmente constrangimentos de natureza logística (e.g., rigidez nos horários) e relacional (i.e., entre cuidadores/as e pessoas idosas), algo que pode dificultar a materialização de projetos de vida.

\section{Conclusão}

Ao longo deste trabalho, tem vindo a sublinhar-se que, numa perspetiva pela rutura, os construtos do EA e da participação cidadã das pessoas idosas devem beneficiar de uma narrativa disruptiva acompanhada de uma nova gramática assente na integralidade, multidimensionalidade e heterogeneidade do processo de envelhecimento e da velhice. Tal significa que, as abordagens analíticas e empíricas que fundamentam o campo concetual e interventivo da Gerontologia surgem favorecidas quando observadas através dos contributos das assistentes sociais envolvidas neste estudo, uma vez que sustentam, conforme tivemos oportunidade de mostrar, lógicas mais sustentáveis e inclusivas em ERPI, nomeadamente naquilo que tem de ver com o (re)desenho de projetos de vida em contextos residenciais.

Arquitetar projetos de vida para e na velhice em ambientes residenciais revelou de forma muito consistente estar apoiado, por um lado em padrões e diretrizes instituídas e por outro lado, embora surjam a um ritmo lento e monótono, em abordagens holísticas, abrangentes e multidimensionais. Este aspeto faz ressoar a urgência de refletir sobre a importância de abordagens participativas capazes de transformar, ou invés de 
simplesmente reforçar e reproduzir modelos e relações de poder (Petriwskyj, Gibson \& Webby, 2018).

O apelo à diferenciação da(s) velhice(s) na arena gerontoinstitucional obriga, por tal razão, a uma constante metamorfose do cuidado, mas também da arquitetação permanente do projeto de vida das pessoas idosas (i.e., desde o dia em que ingressam na ERPI, até à sua cessação), e disto há a referir que o Serviço Social desempenha um papel relevante no reconhecimento das pessoas idosas enquanto um coletivo diferenciado e não estático.

Esta lógica permite garantir projetos de vida para e na velhice fundados nas escolhas/interesses/talentos/necessidades e objetivos das pessoas idosas, sem descorar a sustentabilidade e a conduta das Organizações. Dinâmicas desta natureza permitem (re)aproximar as ERPI da essência e dos princípios de atuação que as fez emergir, entre outros, garantir a "Qualidade, eficiência, humanização e respeito pela individualidade"; "Promoção e manutenção da funcionalidade e da autonomia" e "Participação e corresponsabilização do residente (...) na elaboração do plano individual de cuidados" (Portaria n. ${ }^{\circ}$ 67/2012 de 21 de março do Ministério da Solidariedade e da Segurança Social, 2012), e por outro lado os/as assistentes sociais sobretudo quando se trata de uma profissão intimamente comprometida com os direitos humanos e com a justiça social.

\section{Referências bibliográficas}

Albuquerque, C. P., \& Arvoverde, A. C. B. (2017). Por um Serviço Social renovado: a importância da reflexividade e da estratégia. In C. P. Albuquerque \& A. C. B. Arvoverde (Coord.), Serviço Social Contemporâneo. Reflexividade e estratégia (pp. 1-22). PACTOR - Edições de Ciências Sociais, Forenses e da Educação.

Alimujiang A., Wiensch A., Boss J., Fleischer, N. L., Mondul, A. M., McLean, K., Mukherjee, B., Pearce, C. L. (2019). Association between life purpose and mortality among US adults older than 50 years. JAMA Netw Open, 2(5). https://doi:10.1001/jamanetworkopen.2019.4270

Almeida, H. N. (2012). Envelhecimento, qualidade de vida e mediação social profissional. In, Carvalho, M. (Org). Serviço Social na Saúde, Disposições e práticas de um campo profissional (p.139-181). Pactor - Edições de Ciências Sociais e Política Contemporânea.

Almeida, M. F. A. (2016). Iniciativas de participação cidadã de idosos em Portugal: um estudo exploratório. Análise Social, 219(2), 402-431. http://www.scielo.mec.pt/pdf/aso/n219/n219a06.pdf

Apouey, B. H. (2018). Preparation for old age in France: The roles of preferences and expectations. The Journal of the Economics of Ageing, 2, 15-23. https://doi.org/10.1016/i.jeoa.2017.11.003 
Casado, T., Sousa, L. \& Touza, C. (2020). Older people's perspective about their participation in health care and social care services: A systematic review. Journal of Gerontological Social Work, 68(8), 878-892, https://doi.org/10.1080/01634372.2020.1816591

Chapin, R., \& Cox, E. O. (2002) Changing the paradigm: Strengths-based and empowerment-oriented Social Work with frail elders, Journal of Gerontological Social Work, 36(3-4), 165-179, https://doi.org/10.1300/J083v36n03_13

Crispim, R. (2020). Velhice(s) e participação em estruturas residenciais para idosos percecionadas por pessoas idosas e assistentes sociais: um estudo qualitativo. Revista Portuguesa de Investigação Comportamental e Social, 6(1), 81-96. https://doi.org/10.31211/rpics.2020.6.1.172

Crispim, R., \& Luz, H. A. (2020). Expressões da participação na(s) velhice(s): Dimensões valorizadoras da ativação sénior suscitadas pelo Serviço Social em ERPI. In R. Pocinho et al. (coords). O Envelhecimento como um todo. Livro de Atas do AgeingCongress2020 (pp. 343-354). Thomson Reuters ARANZADI

Bardin, L. (2016). Análise de conteúdo. Edições 70.

Durbin, K. A., Barber, S. J., Brown, M., \& Mather, M. (2019). Optimism for the future in younger and older adults. Journals of Gerontology - Series B Psychological Sciences and Social Sciences, 74(4), 565-574. https://doi:10.1093/geronb/gbx171

Forum para a Governação Integrada. (2014, julho 11-12). Idosos solitários. Problemas sociais complexos: Desafios e respostas. Conferência Internacional. https://bit.ly/3pCTCPB

Foster, L., \& Walker, A. (2015). Active and Successful Aging: A European Policy Perspective. The Gerontologist, 55(1), 83-90. https://doi.org/10.1093/geront/gnu028

Hees, S. van, Horstman, K., Jansen, M., \& Ruwaard, D. (2015). Conflicting notions of citizenship in old age: An analysis of an activation practice. Journal of aging studies, 35, 178-189. https://doi.org/10.1016/j.jaging.2015.09.001

Herazo-Beltrán Y., Quintero-Cruz M. V., Pinillos-Patiño Y., García-Puello F., Núñez-Bravo, N., \& Suarez-Palacio, D. (2017). Calidad de vida, funcionalidad y condición física en adultos mayores institucionalizados y no institucionalizados. Revista Latinoamericana de Hipertension, 12(5), 174-81. https://www.redalyc.org/pdf/1702/170254309009.pdf

José, J. de S., \& Teixeira, A. R. (2014). Envelhecimento Ativo: contributo para uma discussão crítica. Análise Social, XLIX(1. $\left.{ }^{\circ}\right), 28-54$. https://bit.ly/3z5nUQn

Little, B. R. (1983). Personal Projects: A rationale and method for investigation. Environment and Behavior, 15(3), 273-309. https://doi.org/10.1177/0013916583153002

Luz, H. A. (2017, setembro 5-9). Problemas sociais complexos - wicked problems - e intermediação das organizações de economia social: Estratégias adaptativas no campo do envelhecimento ativo (EA) [Apresentação de artigo]. XVIII Congreso Ahila en los márgenes de la historia tradicional. Nuevas miradas de América Latina desde el siglo $X X I$, Espanha.

Marier, P., \& van Pevenage, I. (2017). Three competing interpretations of policy problems: tame and wicked problems through the lenses of population aging. Policy and Society, 36(3), 430-445. https://doi.org/10.1080/14494035.2017.1361636 
Medeiros, M. M., Carletti, T. M., Magno, M. B., Maia, L. C., Cavalcanti, Y. W., \& Rodrigues-Garcia, R. C. M. (2020). Does the institutionalization influence elderly's quality of life? A systematic review and meta-analysis. BMC Geriatrics 20(44). https://doi.org/10.1186/s12877-020-1452-0

Miguel, I., \& Amaro da Luz, M. H. (2014). Envelhecimento ativo multinível: Uma Perspetiva pela Qualidade de Vida. Actas do VIII Congresso Nacional de Sociologia. https://bit.ly/35104I0

Mondaca, M., Josephsson, S., Katz, A., \& Rosenberg, L. (2018). Influencing everyday activities in a nursing home setting: A call for ethical and responsive engagement. Nursing inquiry, 25(2), e12217. https://doi.org/10.1111/nin.12217

Nogueira, M. F., Lima, A. A., Trigueiro, J. von S., Torquato, I. M. B., Henriques, M. E. R. M. H., \& Alves, M. S. C. F. (2016). Comparing the quality of life of institutionalized and non-institutionalized older adults. Uerj Nursing Journal, 24(5), 16. https://doi.org/10.12957/reuerj.2016.28185

Petriwskyj, A., Gibson, A., \& Webby, G. (2018). What does client 'engagement' mean in aged care? An analysis of practice. Ageing and Society, 38(7), 1350-1376. https://doi.org/10.1017/S0144686X17000095

Pinto, C. (2013). Uma prática de empowerment com adultos idosos. In M. I. Carvalho (Coord.), Serviço Social no envelhecimento (pp. 49-65). PACTOR - Edições de Ciências Sociais, Forenses e da Educação.

PORDATA (2021). População activa: por grupo etário (\%). Que países têm uma população empregada e desempregada mais jovem ou mais envelhecida? https://bit.ly/3oa1hEF

Rede Europeia Anti-Pobreza/Portugal. (2017). Estratégia nacional para o envelhecimento ativo e saudável 2017-2025. https://bit.ly/2WGTgLV

Santana, C. S., Bernardes, M. S., \& Molina, A. M. T. B. (2016). Projetos de vida na velhice. Estudos Interdisciplinares sobre o Envelhecimento, 21(1), 171-186. https://bit.ly/36xNNvp

Santos, J. D., Cachioni, M., Yassuda, M., Melo, R., Falcão, D., Neri, A., \& Batistoni, S. (2019). Participação social de idosos: Associações com saúde, mobilidade e propósito de vida. Psicologia, Saúde \& Doenças, 20(2), 367-383. https://dx.doi.org/10.15309/19psd200208

Schenell, R., Ozanne, A., Strang, S., \& Henoch, I. (2020). To make and execute decisions throughout life: A person-centred model that facilitates self-determination in residential care, developed through participatory research. Applied Nursing Research, 55. https://doi.org/10.1016/j.apnr.2020.151318

Teater, B, \& Chonody, J. (2017). Promoting Actively Aging: Advancing a framework for Social Work practice with older adults. Families in Society, 98(2), 137145. https://doi.org/10.1606/1044-3894.2017.98.19

van Dyk, S. (2014). The appraisal of difference: Critical gerontology and the activeageing-paradigm. Journal of Aging Studies, 31, 93-103. https://doi.org/10.1016/j.jaging.2014.08.008

WHO. (2002). Active aging: A policy framework. World Health Organization. 